\title{
Semantic priming in the prime task effect: Evidence of automatic semantic processing of distractors
}

\author{
PALOMA MARÍ-BEFFA \\ University of Wales, Bangor, Wales \\ LUIS J. FUENTES \\ University of Almeria, Almeria, Spain \\ ANDRÉS CATENA \\ University of Granada, Granada, Spain \\ and \\ GEORGE HOUGHTON \\ University of Wales, Bangor, Wales
}

\begin{abstract}
The automaticity of the semantic processing of words has been questioned because of the reduction of semantic priming when the prime word is processed nonsemantically-for example, in letter search (the prime task effect). In two experiments, prime distractor words produced semantic priming in a subsequent lexical decision task, but with the direction of priming (positive or negative) depending on the prime task. Lexico-semantic tasks produced negative semantic priming, whereas letter search produced positive semantic priming. These results are discussed in terms of task-based inhibition. We argue that, given the results from the distractors, the absence of semantic priming does not indicate an absence of semantic activation but reflects the action of control processes on prepotent responses when less practiced responses are needed.
\end{abstract}

When people interact with objects in their environment, multiple properties of these objects are represented in parallel in specialized brain areas. However, only some of these representations will be relevant in guiding current actions. For instance, when picking up a cup, we will be concerned with its shape and weight, in order to control grip shape and lifting force. When filling it with liquid, we will pay more attention to its capacity and stability, to avoid spillage. It is possible, then, that the task-based deployment of attention can influence the relative degree to which various representations control the individual's current behavior-relevant properties being facilitated, and irrelevant ones inhibited (Tipper, Weaver, \& Houghton, 1994). A complicating factor is that a specific object can become strongly associated by frequent practice with just one or two of the actions that could, in principle, be per-

Parts of this research were reported at a meeting of the Experimental Psychology Society, Oxford, 1997. P. M.-B. was supported by a postdoctoral grant from Ministerio de Educación y Cultura (Spain). This research was also supported by Grant PM97-0002 from Dirección General de Enseñanza Superior to L.J.F. We are indebted to Francisco Nievas Cazorla for his advice. We also thank three anonymous reviewers for their helpful suggestions. Correspondence concerning this article should be addressed to P. Marí-Beffa, School of Psychology, University of Wales, Bangor, Gwynedd LL57 2DG, Wales (e-mail: pbeffa@ bangor.ac.uk). formed on it. In this case, the representations relevant to the control of these prepotent actions may become automatically activated to a high degree whenever the object is encountered, irrespective of current goals. In the extreme, the associated actions may even be elicited, as is evidenced by utilization behavior in subjects with prefrontal lobe impairments (Lhermitte, 1983), impulsive behavior in monkeys and young children (Diamond, 1990), and action slips, such as capture errors in normal adults (Reason, 1979). In this case, the need for inhibitory control of the representations eliciting the prepotent response may be particularly strong.

In an experimental context, studies of automaticity and attentional control have frequently used word stimuli where the strongly prepotent response is reading for meaning, which by definition must involve access to lexicalsemantic representations (Stroop, 1935). However, some recent studies using semantic priming, reviewed below, have questioned whether semantic access from words is in fact automatic, suggesting that it requires that participants be involved in some lexical-level task (e.g., lexical decision). If a task such as letter search within a word is used, semantic priming is reduced or eliminated, purportedly indicating a corresponding absence of semantic activation. In the present research, we examine this issue, using a negative-priming paradigm. To summarize, we demonstrate that (1) the absence of semantic priming 
does not necessarily imply that high-level semantic representations have not been accessed by the stimulus word and (2) the nature of the priming effects obtained (facilitatory or inhibitory) is contingent on task demands.

\section{Automaticity in Word Recognition}

A crucial assumption for the hypothesis of automaticity in word recognition is that the mere presentation of a word is enough to activate its representations at all levels (see Posner \& Carr, 1992, for a review). Additional properties of automaticity would include the fact that word processing (1) should not be interfered with by other tasks, (2) should not be influenced by intentions, strategies, or expectancies, and (3) should proceed unconsciously (O. Neumann, 1984). Evidence for the automaticity of word recognition comes mainly from two types of experimental procedures: Stroop interference and semantic priming.

In the Stroop effect, participants take longer to name the ink color of a stimulus word when the word is an incongruous color name (e.g., the word green printed in blue), than when it is congruous (e.g., the word green printed in green; Stroop, 1935). This interference effect is taken as showing that participants cannot prevent the (automatic) accessing of the meaning of the word despite instructions not to do so. The Stroop effect has been found in a variety of tasks, and it constitutes one of the most robust effects in the attention literature (see MacLeod, 1991, for a review). For instance, interference effects occur not only when the relevant attribute (the ink color) and the irrelevant attribute (the word) belong to the same object, but also when the color and the word are presented separately at different degrees of eccentricity (distance from the target; Gatti \& Egeth, 1978).

In semantic priming, if a target word, such as $d o g$, is preceded by a semantically related prime, such as cat, it is processed more efficiently than when preceded by an unrelated prime, such as chair (Meyer \& Schvaneveldt, 1971; Neely, 1977, 1991). This facilitation in responding has been taken as evidence for the automatic spreading of activation from the prime representation to the target representation in the memory network (see Collins \& Loftus, 1975), at least when a short prime-target stimulus onset asynchrony (SOA) is used. For instance, Neely (1977) found that semantic priming may be observed if participants are instructed to expect specific exemplars of a category when given the name of a different category (e.g., to expect birds when the label body is presented), but only when the prime-target SOA is long. With a short SOA, only well-established associations produced semantic priming irrespective of instructions given to participants. In other words, without enough time to build an expectation, activation spreads automatically between nodes that have been associated through extensive experience.

Further support for the hypothesis of automaticity in word recognition comes from studies that have measured semantic priming effects from parafoveally presented stim- uli. For instance, Fuentes and colleagues (Fuentes, Carmona, Agis, \& Catena, 1994; Fuentes \& Tudela, 1992) have reported semantic facilitation from parafoveal words presented $4^{\circ}$ of visual angle from fixation. They also argued that semantic priming from parafoveal words was automatic, since it was not affected either by a simultaneous task or by masking, in contrast to semantic priming from foveal words, which was affected (reduced) by both (Fuentes et al., 1994).

Taken together, the results of Stroop interference in its various forms and of semantic priming studies with short SOAs between prime and targets or with parafoveal presentations support the view that semantic processing of words can occur without attention, in an automatic way.

\section{The Automaticity Hypothesis Challenged}

The automaticity hypothesis of word recognition has been challenged in several studies in which facilitation in semantic priming tasks or interference in Stroop tasks is reduced or even eliminated (Besner, Smith, \& MacLeod, 1990; Carr \& Dagenbach, 1990; Chiappe, Smith, \& Besner, 1996; Friedrich, Henik, \& Tzelgov, 1991; Henik, Friedrich, Tzelgov, \& Tramer, 1994; Margolin, 1983; Smith, Theodor, \& Franklin, 1983; Stolz \& Besner, 1996). Such findings are typically deemed to be contrary to what is expected of an automatic process (Neely, 1977; Posner \& Snyder, 1975).

An important variable found to affect semantic priming is the nature of the task performed on the prime word (referred to as the prime task effect). For instance, when participants are told to search the prime word for a letter, semantic priming of a following target word is virtually eliminated (Besner et al., 1990; Friedrich et al., 1991; Smith, 1979; Smith et al., 1983). In a study by Henik et al. (1994), participants were required to make lexical decisions to targets while the prime task was varied between groups. The prime task could require either a deep or a shallow processing of the prime word. For the deepprocessing group, the prime task was to read aloud the prime word. For the shallow-processing group, the prime task was to search the prime word for a particular letter. Semantic priming occurred only for the deep-processing group. Thus, semantic priming seems to depend on whether the task or mental set (Stolz \& Besner, 1996) requires attention to be directed to high-level properties of prime words, as in lexical decision tasks (Neely, 1991). When the task requires attention to be summoned to the level of the letter (as in the Henik et al. study), a block between the lexical and the semantic levels of processing may occur, activation of the letter level being preserved through feedback from the lexical level (see Stolz \& Besner, 1996). In this case, little or no attention is committed to the semantic level of the prime, and no semantic facilitation (or very little) is then observed (see Friedrich et al., 1991; Stolz \& Besner, 1996).

As Besner, Stolz, and Boutilier (1997) have pointed out, this elimination of the semantic priming effect has been reported frequently in the last decade, and it is a result 
that supposedly challenges at least a strong view of the automatic nature of semantic priming. However, some authors are still reluctant to abandon the idea of reading as an automatic process, probably because Stroop interference by words in color-naming tasks is a robust effect that occurs even when the colored stimulus and the word are presented separately at several degrees of eccentricity (see Gatti \& Egeth, 1978). The complete elimination of the effect has not been reported often, even though some factors do reduce it - for example, adding a neutral word along with the color word (Kahneman \& Henik, 1981), coloring a single letter rather than the whole word (e.g., Besner et al., 1997), or presenting the stimuli in a location subject to inhibition of return (Vivas \& Fuentes, 2000). To our knowledge, only Besner et al. (1997) have reported a total elimination of the Stroop interference, this occurring when only a single letter of the stimulus word was colored and no congruent trials were included.

These results challenge a strong version of the automaticity hypothesis of word processing in word recognition. However, in the present study, we attempt to demonstrate that, when the prime task requires low-level processing of words, the lack of (positive) semantic priming does not necessarily imply the lack of semantic processing.

\section{Negative Priming in Word Recognition}

From the studies above, one could argue that the absence of certain effects (semantic priming and Stroop interference) makes a strong case against automatic semantic processing in word recognition tasks. This has important implications for models of word recognition that claim that activation occurs at all levels of word processing in a rather automatic way (e.g., McClelland \& Rumelhart, 1981). At first sight, the fact that semantic priming can be reduced or even eliminated when the task requires a response at the letter level suggests that semantic activation may be blocked, a conclusion also in line with early theories of selective attention (Broadbent, 1958; Treisman, 1969).

However, it should be noted that arguing from an absence of semantic priming is arguing from a null result, and such arguments must be treated with caution. A similar point has been made by Driver and Tipper (1989) with respect to claims that the absence of distractor interference in selection tasks necessarily means that distractors are not processed (Francolini \& Egeth, 1980). Driver and Tipper showed that distractor stimuli that did not produce interference with responses to semantically related targets (and hence might be considered not to have been processed) nevertheless produced subsequent negative priming. (Negative priming is the demonstration that people take longer to respond to a target that was recently ignored. Concretely, if a to-be-ignored distractor, such as the picture of a dog, subsequently becomes the target, responses to it will be slowed, as compared with the condition in which the target was not the previous distractor [Tipper, 1985].)
The finding of negative priming implies that both the target and the distractor are processed automatically but that the distractor's activation is subsequently suppressed in the process of target selection (Fuentes \& Tudela, 1992; Houghton \& Tipper, 1994; Neill, 1977; Yee, 1991). The negative priming study of Yee is particularly relevant here. Yee presented participants with two tasks: (1) to detect the orientation of a target geometric figure in the prime display and (2) to make a lexical decision on targets in the probe display. The prime display could also contain two distractor words presented above and below the target figure $200 \mathrm{msec}$ after the onset of the target. In some conditions, the to-be-ignored words in the prime display were semantically related to the subsequent target in the probe display. Reaction times (RTs) were slowed in this condition, as compared with the condition in which the prime distractors and the probe target were not related. This negative-priming effect suggests that the distractor words were processed semantically, although subsequently inhibited, despite being presented at $4.5^{\circ}$ of visual angle from the focus of attention. Most important, semantic processing occurred even when participants were involved in a low-level prime task (orientation detection).

\section{The Present Study}

In the present research, we combined the prime task procedure used in previous semantic priming studies (Henik et al., 1994) with the presentation of distractor material as in the Yee (1991) study. This kind of presentation allowed us to separate relevant from irrelevant information in different objects so that we could assess semantic priming from both attended and unattended words (see Fuentes et al., 1994; Fuentes \& Tudela, 1992; Ortells \& Tudela, 1996). Manipulating the prime task with such a procedure should allow us to replicate the reduction in semantic priming from foveal words found in previous studies. However, the main concern of the study was to examine whether the level of processing required for the prime target also affects the level of analysis of an irrelevant distractor word. According to current accounts of the prime task effect (e.g., Chiappe et al., 1996; Smith, 1979), allocation of attention to the letter level blocks semantic level processing in general, and hence, no semantic priming effect from distractors would be predicted. This point will be further discussed in the Discussion section of the present experiment.

In the present experiments, we manipulated the nature of the prime task. The participants were presented with prime and probe displays sequentially, composed of one central target and two distractors (presented above and below the target). The participants were told to make lexical decisions to targets in the probe displays but were required to perform a different task on targets in the prime displays. The prime tasks varied in the level of processing required to perform the task. The low-level task was to search the prime word for a letter (Experiments 1-2). High-level tasks were lexical decision (Experiment 1) and target categorization (Experiment 2 ). The prediction 
was that if semantic activation is blocked when participants are involved in a low-level prime task, semantic priming of lexical decision should not be obtained (or it should be much reduced) either from prime targets or from distractors in the low-level prime task condition, as compared with conditions in which a high-level prime task is used.

\section{GENERAL METHOD}

The following experiments used a new design that adapts the traditional prime task procedure to a negative-priming paradigm. In this section, we describe the basic procedure used here to display the stimuli and to search for the letter in the prime target.

\section{Positioning of Stimuli}

Each display contained three stimuli arranged vertically. The central stimulus was always the to-be-attended target item. This was closely flanked above and below by two identical distractor stimuli, which the participants were told to ignore. It was intended that this symmetrical configuration would facilitate the spatial direction of attention to the target. We also note that, although negative priming decreases as the number of distractors increases (Houghton, Tipper, Weaver, \& Shore, 1996; E. Neumann \& DeSchepper, 1992), this occurs only when the distractors are different and, consequently, activate different units in memory (Houghton et al., 1996). When both distractors are the same, they may collaborate in the activation of the same unit, leading to a more robust negative-priming effect (Colmenero, 1996), as predicted by the reactive inhibition model of Houghton and Tipper (1994). It is, thus, not unusual to use more than one identical distractor in negative-priming studies, although normally the two distractors flank the target on the horizontal axis (Fuentes, Humphreys, Agis, Carmona, \& Catena, 1998; Neill, 1997; Neill, Lissner, \& Beck, 1990; Neill \& Terry, 1995). However, with word stimuli, as used here, this arrangement might induce a left-to-right reading strategy, as is suggested by the data from Ortells and Tudela (1996). Hence, we preferred the vertical arrangement.

Finally, two identical distractors were also presented in the probe, since negative priming has been found to increase with distracting stimuli in the probe display (Moore, 1994; Tipper \& Cranston, 1985).

\section{The Letter Search Task}

When compared with the standard design for the prime task effect, one significant change in our experiments is the way in which the participants had to search for the letter. In the standard version (see, e.g., Besner et al., 1990; Henik et al., 1994), the target letter is presented simultaneously with the search word, appearing above it repeated in a string-for example,

\section{RRRR}

\section{CARD}

-and participants are instructed to attend to both stimuli and to decide whether they share a letter in common. In the present study, since we needed to display two identical to-be-ignored stimuli, the letter search had to be carried out in a different way. Therefore, in letter search primes, the target letter was first presented alone at fixation, followed by the prime display (Figure 1). Note that this new procedure also removes a potential problem with the standard design. The traditional procedure requires attention to be directed to two objects during the letter search task. However, in control tasks used in the same experiments (e.g., reading a word aloud), attention is oriented to just one object. Hence, the attentional demands of the two prime tasks are not equivalent. The version of the letter search task used here provides a better comparison between the two prime tasks.

\section{EXPERIMENT 1}

In this experiment, we sought to replicate the prime task effect of the previous studies (e.g., Henik et al., 1994) with this combined procedure and to assess how a lowlevel task on prime targets affects semantic priming from both targets and distractors. We used the lexical decision task as a high-level task because it has proved to be sensitive to semantic priming from both target and distractor words (Fuentes \& Tudela, 1992; Henik et al., 1994; Ortells \& Tudela, 1996; Yee, 1991). We used letter search as a low-level task because it has been shown to eliminate semantic priming from attended prime words (e.g., Henik et al., 1994).

In the following experiment, prime task was a betweengroup factor. We refer to the group doing the lexical decision prime task as the lexical decision group and the group doing the visual search prime task as the letter search group.

\section{Method}

Participants. The participants were 36 undergraduate students from the third year of the psychology program at the University of Almería. They received course credit for their participation in a single session, and all of them had normal or corrected-to-normal vision. All were native speakers of Spanish.

Apparatus and Stimuli. The stimuli were presented on a color monitor (using a VGA card) of an IBM-compatible computer. The computer controlled all the stimulus events and timing operations. The participants responded by pressing the $M$ and $V$ keys of the computer keyboard.

The stimuli were strings of uppercase letters programmed in Microsoft QuickBASIC. Each wordlike stimulus, the fixation point $\left({ }^{*}\right)$, and the other stimuli presented for the instructions were printed in white (ASCII code number 15) on a black background (ASCII code number 0$)$. Each letter was $5 \mathrm{~mm}$ high and $4 \mathrm{~mm}$ wide $\left(0.48^{\circ}\right.$ and $0.38^{\circ}$ of visual angle, respectively), corresponding to letters from a $24 \times 40$ text mode.

Each string was either a Spanish word or a pseudoword (i.e., a pronounceable string of letters without any meaning in Spanish), from four to six letters in length (with an average of 5.14, $S D=$ 3.73). The words were members of one of four categories: animals, body parts, food, or geographic formations. For each category, 36 words were chosen, forming 18 pairs of both frequent and associated words. The frequency values were obtained from Juillan and Chang-Rodriguez (1964), with an average of $12.24(S D=28.44)$. The association strength between paired words was obtained from the Algarabel, Sanmartín, García, and Espert (1985) norms and had an average of $8.23 \%(S D=9.83 \%)$.

This produced a total of 144 different words. From the 36 words in each category, 24 were selected for use in the related conditions (related attended [RA] and related distractor [RD]; see the Design and Procedure section for a full description of the conditions), 12 were used in the prime, and 12 were probe targets. The remaining 12 words ( 6 used in the prime display and 6 in the probe target) were re-paired with words from the other categories and used as unrelated (UR) pairs. Overall, there were 72 pairs of words ( 4 categories $\times 18$ pairs) used for the relevant experimental conditions. The as- 
signment of the pairs to each of the three experimental conditions was varied across participants in each group. To control for other potential confounds, three analyses of variance (ANOVAs) were performed on word length, printed frequency, and associative strength, with the experimental conditions as factors. There was no significant effect in any of the analyses, indicating that the pairs used for the different conditions did not differ in length, printed frequency, or associative strength.

Once the 72 experimental pairs were constructed, 2 additional words per trial had to be included, 1 for the prime and 1 for the probe. For this, the same set of 144 words was used, and the 2 extra words in each trial were chosen so that they were categorically unrelated both to each other and to the words in the experimental pair.

The use of a lexical decision task requires pseudoword trials. The 72 pseudowords were obtained from the 72 probe words by changing one of the letters (e.g., herina instead of harina; in English, this would be equivalent to saying rivar instead of river) or by interchanging the position of two letters within a word (e.g., namo instead of mano; in English, nart instead of rant). These 72 pseudowords were used as probe targets in 72 control trials for the lexical decision task of the probe. The same prime displays used for the experimental conditions were used for these control trials by repairing the prime and the pseudoword probes in such a way that there was never any relation between the prime words and the word from which the probe pseudoword was derived.

For the participants in the lexical decision group, the 144 trials described above were duplicated to create another 144 trials in which the prime target string was a pseudoword. To do so, the prime target was replaced by a pseudoword (created by using the procedure described above) and, in the case of the related condition, repaired in such a way that there was no relation between the prime and the probe.

For the letter search group, the same set of 288 trials was used but with the pseudowords used as targets for the prime lexical decision task being replaced by the words from which they were derived. Since the prime task consisted of a present/absent decision, the target letter was present in only half of the trials. However, in the experimental conditions, the target letter was always present. With this practice, we can keep the same pattern of responses from prime to probe in both groups; that is, all the analyzed responses were obtained on trials in which both the prime and the probe responses were affirmative (see the Design and Procedure section). The target letter was never present in either prime distractors or any stimuli from the probe display.

Each related pair was presented only once in the experiment. However, in the lexical decision group, the individual words were repeated five or six times in order to create all the conditions described above. A further two repetitions were required for the letter search prime task, since there were no pseudoword primes.

The large number of control trials used in the experiment meant that the final proportion of related condition trials was only .16 . Half of these (.08 of the total) corresponded to the RA condition, in which priming from the prime target might be found. This proportion seems sufficiently low to preclude the use of ad hoc strategies, such as consciously anticipating probe targets related to prime display elements (see, e.g., Neely, 1977).

The target stimulus was displayed in the center of the screen with two identical distractors displaced $1 \mathrm{~cm}$ above and below fixation $\left(0.95^{\circ}\right.$ of visual angle). The screen was located about $60 \mathrm{~cm}$ from the eyes.

Design and Procedure. After the display of a cue at fixation (an asterisk for the lexical decision group and the search letter for the letter search group; see Figure 1), two sets of stimuli were presented: the prime and the probe displays. Each display was composed of two kinds of stimuli: the target and distractors.
Instructions were presented on the screen of the computer. The participants were randomly assigned to two groups: those that performed the lexical decision task for both the prime and the probe displays and those that performed a letter search task for the prime display and the lexical decision task for the probe display (see Figure 1). For the participants in the lexical decision group, the task was always to attend to the target stimulus and decide, as soon as possible without committing any mistakes, whether it was a word (by pressing the $\mathrm{M}$ key on the keyboard) or a pseudoword (by pressing the $\mathrm{V}$ key with the other hand). For the prime display, the participants in the letter search group had to decide whether the letter that had previously appeared at fixation was present (by pressing the $M$ key) or absent (by pressing the V key) in the target. For the probe display, the task was a lexical decision identical to that performed by the lexical decision group for the prime display. Both groups were told that response latencies and mistakes were recorded and that responses in a given trial would not be valid if the time taken to respond was too long or there was a mistake. It was also stressed that distractors should be ignored in order to facilitate performance of the task.

The experimental conditions for testing priming were obtained according to the relationship between the prime and the probe stimuli as follows: In the RA condition, the prime target word was semantically associated to the probe target word; in the RD condition, the prime distractor word was semantically associated to the probe target word; and in the UR condition, none of the stimuli from the prime to the probe displays were associated. The participants from both the lexical decision and the letter search groups received exactly the same type of trials (with the exception that pseudowords did not occur in the letter search prime); thus, the control of variables was almost identical for both groups (see the previous section).

Each trial started when the fixation cue (or letter, in the letter search group) appeared on the screen for $500 \mathrm{msec}$, followed by the prime display after an interval of $150 \mathrm{msec}$. As soon as the response to the prime target was performed, the prime display disappeared and was replaced by the probe display after $300 \mathrm{msec}$ ( $150 \mathrm{msec}$ of which could be used for auditory feedback). After this second response, the instruction PRESS BAR was displayed without any time limit. This terminated the trial, and the participants could start the next pair of displays by pressing the space bar whenever they felt ready. The next trial began $200 \mathrm{msec}$ after they pressed the space bar and the screen was blank. The participants received auditory feedback (a 150-msec beep) for any errors made in either the prime or the probe responses.

The order of trials was randomized by the computer for each participant. Each participant performed 288 trials, of which just 72 belonged to the three experimental conditions ( 24 observations per cell); the rest were control conditions. There were four blocks of 72 trials, separated by three rest periods. Before the experimental session, each participant received 24 practice trials ( 2 randomly selected from each experimental condition, and the rest from the corresponding control conditions).

\section{Results}

As a general procedure used in every experiment of this paper, RT analyses were conducted for trials in which both the prime and the probe responses were correct. Only those RTs above $200 \mathrm{msec}$ and below $2,000 \mathrm{msec}$ were considered for the analysis. As a result of this trimming, $0.15 \%$ of the overall responses were discarded in Experiment 1 .

The main results are shown in Table 1. Participant medians of RTs to the probe displays were analyzed in a two- 


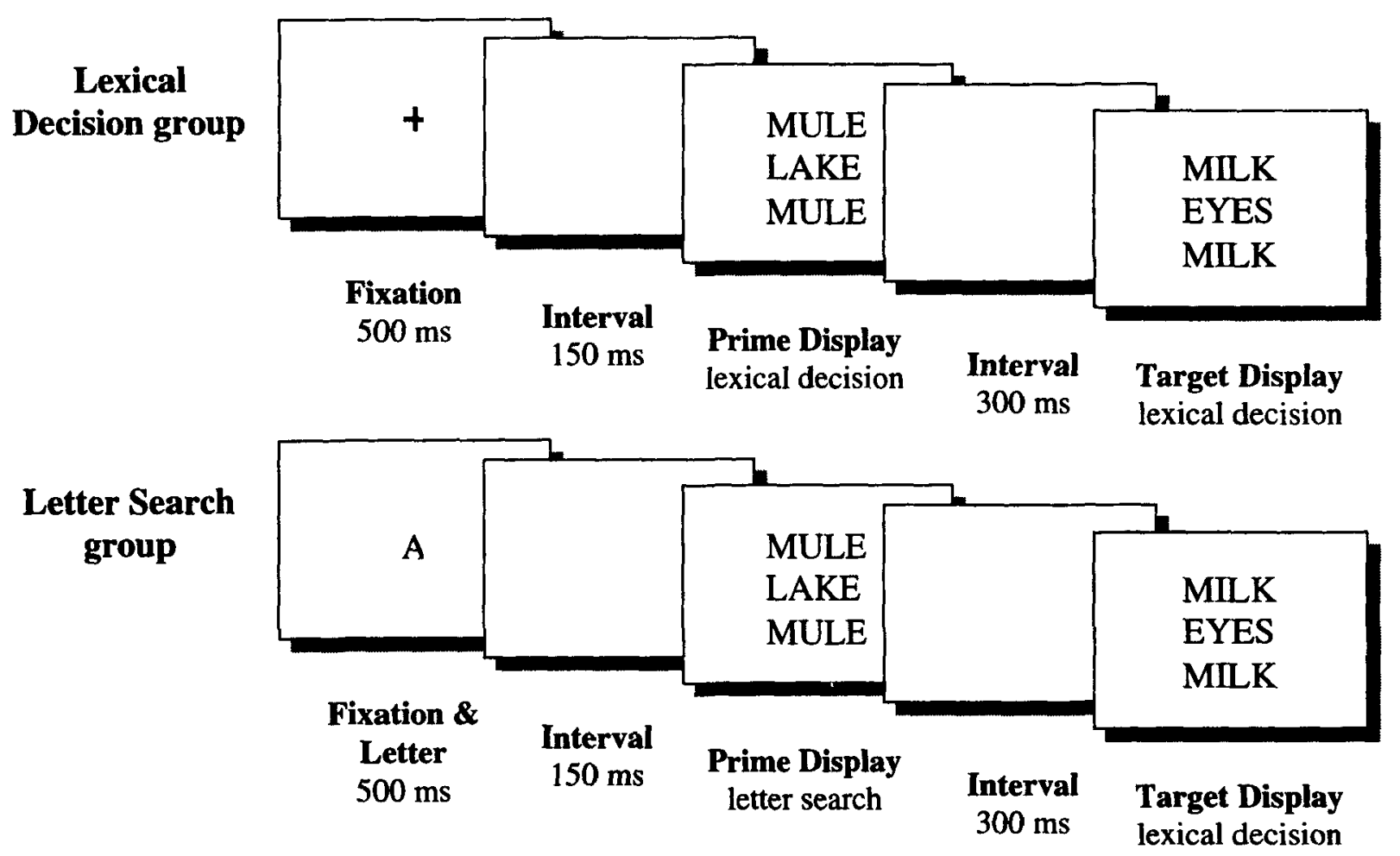

Figure 1. An illustration of the task manipulation in Experiment 1. The temporal sequence is represented from left to right in the figure. The participants are required to attend to the stimulus displayed in the center of the screen and to ignore the two distractors above and below the target.

way ANOVA for a factorial design with two variables: a within-subjects factor of conditions (RA, UR, or RD) and a between-group factor of task (lexical decision or letter search). The prime task produced a general main effect on the responses to the probe display $[F(1,34)=$ $\left.20.09, M S_{\mathrm{e}}=18,027.47, p<.001\right]$, owing to an increase in the global RTs to the probe when the prime task was the letter search. There were also reliable effects for conditions $\left[F(2,68)=3.14, M S_{\mathrm{e}}=705.11, p<.05\right]$ and for the task by conditions interaction $[F(2,68)=29.91$, $\left.M S_{\mathrm{e}}=705.11, p<.001\right]$.

Accordingly, we conducted an analysis of the interaction. Semantic facilitation from the attended prime word (UR-RA) was smaller in the letter search group than in the lexical decision group $\left[F(1,34)=11.49, M S_{\mathrm{e}}=\right.$ $695.68, p<.005]$. In fact, semantic priming was significant in the lexical decision group $[F(1,17)=12.06$, $\left.M S_{\mathrm{e}}=994.01, p<.005\right]$, but not in the letter search group. Regarding effects of prime distractor words (the UR-RD comparison), negative priming from distractors was found in the lexical decision group, whereas the letter search group showed positive priming from distractors $\left[F(1,34)=29.10, M S_{\mathrm{e}}=457.94, p<.001\right]$. Relative to the distractors, both semantic negative priming in the lexical decision group $\left[F(1,17)=10.09, M S_{\mathrm{e}}=430.54, p<\right.$ $.01]$ and semantic positive priming in letter search group $\left[F(1,17)=19.52, M S_{\mathrm{e}}=485.35, p<.001\right]$ were signifi- cant. There were no significant differences in semantic positive priming from the target and distractor in the letter search group. Errors for the responses to the probe display were analyzed with an ANOVA that showed no reliable main effects.

We also analyzed the responses to the prime displays. The overall RT to the prime task was $746 \mathrm{msec}$ in the lexical decision group and $802 \mathrm{msec}$ in the letter search group. Analyses concerning the responses to the prime display showed no significant differences between groups (lexical decision, letter search) in the time taken to respond, although the letter search task was apparently slower (around $50 \mathrm{msec}$ ). Finally, the estimated SOA averaged $1,046 \mathrm{msec}$ (in the lexical decision group) and $1,102 \mathrm{msec}$ (in the letter search group).

\section{Discussion}

The results demonstrate that when participants attend to letters in a target word, positive semantic priming from ignored words can be observed in a subsequent probe. Nevertheless, the type of task performed on the prime had an effect on the semantic priming obtained from both the attended and the ignored words. Also, positive semantic priming from the attended word was reduced for the prime visual search task, replicating the results of Henik and his group. However, under these conditions, negative semantic priming for the ignored distractors was not 
Table 1

Means (in Milliseconds) of the Median Reaction Times to the Probe Display, Standard Deviations (SDs), and Error Rates (\%E) for Both the Lexical Decision and the Letter Search Groups in the Relevant Conditions of Experiment 1

\begin{tabular}{lrrrrrr}
\hline & \multicolumn{3}{c}{ Condition } & & \multicolumn{2}{c}{ Priming Effect } \\
\cline { 2 - 3 } Prime Task & RA & RD & UR & & $\begin{array}{c}\text { UR-RA } \\
\text { (Target) }\end{array}$ & $\begin{array}{c}\text { UR-RD } \\
\text { (Distractor) }\end{array}$ \\
\hline Lexical decision & & & & & -17 \\
$M$ & 548 & 600 & 583 & 35 & \\
$S D$ & 80 & 86 & 77 & & 39 \\
$\% \mathrm{E}$ & 8 & 11 & 7 & & \\
Letter search & & & & & \\
$M$ & 682 & 658 & 697 & 15 & \\
$S D$ & 99 & 81 & 71 & & \\
$\% \mathrm{E}$ & 3 & 4 & 4 & & \\
\hline
\end{tabular}

Note-RA, related attended; RD, related distractor; UR, unrelated.

observed; instead, distractors produced positive priming. When the prime task required the processing of lowlevel features - that is, the search for a letter in the letter search group-RTs where slower than for the lexical decision task for both the prime and the probe displays.

The global increase in RTs in the letter search group may be due simply to task switching (Allport, Styles, \& Hsieh, 1994). A similar result was reported in the Henik et al. (1994) study. Henik et al. studied changes in facilitation as a function of the type of processing required for the prime task. As in our study, all the participants performed lexical decision on probe targets, but half did naming of the prime target, whereas the other half did letter search. Henik et al. found an increase in RTs and a decrease in facilitation for the letter search condition. They argued that these longer RTs in the letter search condition reflect costs from the change in the level of representation required in the two tasks, and not from the task switching itself. Our results may be due to the same mechanisms as those described by Henik et al.

The critical question examined in the first experiment was whether semantic processing of words is taking place while a low-level property of a target word is attended to, even though semantic priming is not observed. This would indicate that the absence of semantic priming from the target word does not reflect the lack of semantic processing. We have observed a reduction in the semantic priming obtained from the target word when participants attend to its letters. However, semantic priming from the distractor word in this group was significant. The following hypotheses are not compatible with this result: (1) Ignoring one word to better process another prevents semantic activation from the ignored word (mere withdrawal of attention); (2) performing a letter level task on words prevents semantic level processing from taking place at all (Kahneman \& Henik, 1981; Smith, 1979); and (3) semantic processing requires the allocation of limited resources (Chiappe et al., 1996).

We believe that the rejection of these three hypotheses makes it difficult to maintain that the reduction in seman- tic facilitation following letter search is due to an absence of semantic activation from the target word. To make this conclusion more concrete requires consideration of the specifics of various accounts of the prime task effect.

Chiappe et al. (1996) propose an account in terms of resources. They suggest that the letter search task places heavy demands on the letter level of the word-processing system, which are met by the allocation of some general, and limited, processing resource to this level. This leaves less of this resource for semantic activation, causing a reduction of priming. Note that this resource allocation is taking place within the word-processing system as a whole and, hence, any reduction of resources to the semantic level would affect the semantic processing of any word, attended or otherwise. Our results contradict this hypothesis; distractor words produce semantic priming effects. Whatever these putative resources are, either they are still sufficient for semantic processing, or they are not needed.

Stolz and Besner (1996) provide an alternative account in terms of activation blocking, in an interactive activation framework. Normally, activation spreads from nodes at the word level to nodes representing semantic or conceptual elements. It is proposed that during letter search, the word level is still activated but further spread of activation to semantics is blocked. No specific mechanism for achieving this blocking is described; however, Stolz and Besner propose that it

could be due to the letter search task biasing the system to monitor the word and letter levels rather than the semantic level. ... Blocking activation via the [word to semantics pathway] would preclude activation of any semantic associates of the prime, and hence, eliminate semantic priming. (p. 1170)

The important point is that the account proposes a generalized blocking of semantic activation owing to the "biasing" of the system to monitor the word and letter levels. Our data clearly indicate that no such generalized blocking of word-to-semantic activation takes place.

It is perhaps possible that the above accounts might be refined so that the implicated resource or blocking mechanisms somehow act specifically on the attended target word, rather than over whole levels of representation. Semantic activation of the attended word would not take place, whereas distractors would be unaffected. Although this possibility is easy to state, envisaging the mechanisms that would actually achieve this is somewhat harder. Nevertheless, we do believe that our data support the idea of some control process that is specifically engaged by the processing of the attended target.

The observed reduction of semantic facilitation following letter search may be due to a control process aimed at improving performance in the visual search task. With Stroop-like stimuli, it is well known that the distractor word is being processed not just because it produces strong interference in naming the color of the ink (Stroop, 1935), but also because it produces negative 
priming in the processing of the relevant color in the subsequent display (see, e.g., Dalrymple-Alford \& Bundayr, 1966; Neill, 1977). One of the most common explanations of the Stroop effect is that whole words activate responses faster than do their low-level constituent features (such as ink color or, in our study, letters), because wholeword reading is the task most commonly associated with written words. A strategy directed at reducing the level of automatic activation of word representations would assist the performance of the task at the letter level. Therefore, the reduction in semantic priming in the letter search condition can be explained as being due not to a general blocking in the flow of semantic processing, but to a targeted inhibitory control process operating at the (taskirrelevant) lexico-semantic level.

In support of this idea, some authors have reported negative semantic priming from a target word when attention was directed to its letters (Besner et al., 1990). It is important to note, however, that negative semantic priming from distractor words is not a common result, whatever the prime task used (see Fox, 1995, for a review of the findings). However, the control processes we are postulating act on the target word (as opposed to distractor words) to reduce automatic (but task-irrelevant) activation and, hence, may be different from those responsible for distractor inhibition during selection.

The observed change in distractor priming, from negative in the lexical decision condition to positive in the letter search condition, was rather surprising. If directing attention to low-level features of targets (as in the letter search condition) interrupts the flow of semantic processing in general, less negative semantic priming would have been expected (than in the lexical decision condition), since the distractor words would not have been processed to lexico-semantic levels. On the other hand, if distractors are being automatically processed until their semantic representations are reached, irrespective of the task, we might have expected to obtain negative semantic priming, owing to the need to suppress them. Our results do not accord with either prediction but show, rather, a strong positivepriming effect.

These results are very intriguing; however, it is important to note that the two groups, letter search and lexical decision, were not totally comparable. In the lexical decision group, the same response took place for both the prime and the probe displays. In the visual search group, on the other hand, the response changed from prime to probe. It is possible that task switching, rather than the low level of representation required by the prime task, caused the positive priming from the distractors. In the next experiment, we explored this possibility.

\section{EXPERIMENT 2}

In this experiment, we examined whether task switching might explain the results of the previous experiment. If the switching of tasks in the letter search group produces the change in the direction of distractor semantic priming from negative to positive, we would expect the consequent loss of negative priming to occur whenever the prime and the probe task are different.

In this experiment, the participants were instructed to perform a lexical decision task for the probe, but, in contrast to the first experiment, lexical decision was not used for the prime. Instead, both groups had to change task from the prime to the probe. One group had a letter search prime task (as in Experiment 1), whereas the other group had to categorize the prime target. The only difference was the kind of representation required by the prime task. In particular, the categorization task required semantic processing, whereas letter search did not. If the absence of negative priming in the letter search group in Experiment 1 was caused by the task switching, we would expect the same pattern for the categorization condition in this experiment.

\section{Method}

Participants. Thirty-two undergraduate students from a thirdyear psychology course at the University of Almería participated in this experiment. None participated in the first experiment. They received course credit for their participation in a single session. No visual or reading problems were reported. All of them were native Spanish speakers.

Apparatus and Stimuli. The same 144 words (grouped into 72 pairs) were used in this experiment as in the first experiment. Each pair was presented only once in the whole experiment, but the individual words were repeated five times in order to create the irrelevant and unrelated distractors in the probe displays, the irrelevant prime stimuli in the experimental conditions, and the prime target and distractors for the control conditions with pseudoword probe targets. Physical and temporal parameters were similar to those used in Experiment 1. The only change was in the keys used to respond to the prime task in both groups. For the group executing the categorization prime task, four keys (D, F, K, and L) were used to denote the four stimulus categories to which the prime targets belonged. In the letter search group, two of these keys ( $F$ and $K$ ) were used for the letter search task in the prime display. As in the previous experiment, the $M$ and $V$ keys were used for the lexical decision tasks in the probe display. Note that for both groups, the response set changed from the prime to the probe.

Design and Procedure. For the letter search group, the experimental conditions, instructions about the tasks, and other procedural parameters were basically the same as those used for the same group in the previous experiment. The participants in the categorization group had to press one of four keys to designate the category of the prime target. For the probe, they performed the same lexical decision task as the letter search group. Every task had to be performed as fast as possible while avoiding mistakes. In the categorization group, the participants could consult a sign over the keyboard that indicated the categories and the corresponding keys. Although the experimental conditions (RA, RD, and UR) were the same as those in the previous experiment, the control conditions changed. The prime target stimulus was always a word, and the control conditions concerned the inclusion of pseudoword targets in the probe display (for these control conditions, as in the previous experiment, the probe pseudoword targets were re-paired in order to avoid any relationship between prime words and probe target pseudowords). In this case, the letter to be searched for was present in half of the trials corresponding to the experimental conditions ( 36 of 72) and absent in the remaining half. This was an important change from the previous experiment. To recap, in Experiment 1, the relevant responses for the lexical decision group always oc- 
Table 2

\begin{tabular}{|c|c|c|c|c|c|}
\hline \multirow{3}{*}{ Prime Task } & \multirow{2}{*}{\multicolumn{3}{|c|}{ Condition }} & \multicolumn{2}{|c|}{ Priming Effect } \\
\hline & & & & \multirow{2}{*}{$\begin{array}{l}\text { UR-RA } \\
\text { (Target) }\end{array}$} & \multirow{2}{*}{$\begin{array}{c}\text { UR-RD } \\
\text { (Distractor) }\end{array}$} \\
\hline & $\mathrm{RA}$ & RD & IIR & & \\
\hline \multicolumn{6}{|c|}{ Categorization } \\
\hline$M$ & 672 & 728 & 716 & 44 & -12 \\
\hline$S D$ & 71 & 90 & 84 & & \\
\hline$\% \mathrm{E}$ & 14 & 19 & 16 & & \\
\hline \multicolumn{6}{|l|}{ Letter search } \\
\hline \multicolumn{6}{|l|}{ Present } \\
\hline$M$ & 670 & 657 & 685 & 15 & 28 \\
\hline$S D$ & 34 & 43 & 55 & & \\
\hline$\% \mathrm{E}$ & 4 & 6 & 6 & & \\
\hline \multicolumn{6}{|l|}{ Absent } \\
\hline$M$ & 685 & 689 & 714 & 29 & 26 \\
\hline$S D$ & 83 & 66 & 58 & & \\
\hline$\% \mathrm{E}$ & 7 & 9 & 11 & & \\
\hline \multicolumn{6}{|l|}{ Collapsed } \\
\hline$M$ & 679 & 676 & 702 & 23 & 26 \\
\hline$S D$ & 49 & 51 & 57 & & \\
\hline$\% \mathrm{E}$ & 6 & 8 & 8 & & \\
\hline
\end{tabular}

Note-Data from the letter search group are presented separately, depending on the presence of the prime letter in the prime word (present or absent). In addition, the collapsed condition contains the means of the medians of both the present and the absent trials together. RA, related attended; RD, related distractor; UR, unrelated.

curred in trials in which the affirmative response was repeated from the prime to the probe. Accordingly, in order to keep constant the pattern of responses from the prime to the probe displays, in the experimental conditions the target letter in the letter search group was always present in the prime display. In the present experiment, responses were bound to change from the prime to the probe in the categorization group; thus, we could include target-absent trials in the experimental conditions. An additional advantage of the change was the possibility of analyzing semantic priming effects following the letter search, depending on whether the letter was present or absent in the prime string. Mirroring the distribution of trials for the experimental conditions, half of the control trials with pseudoword probe targets contained the letter in the prime target word, whereas in the other half the letter was absent.

The number of trials per cell was kept constant at 24 , as in the previous experiment. The only difference was that the letter to be searched for was present in the prime target in only half of the trials. This was to keep the proportion of related trials as low as possible (.16 for the RA condition and .16 for the RD condition). The participants were required to complete 144 trials, 24 from each of the three experimental conditions mentioned above and 72 control trials with pseudowords as probe targets.

These 144 trials were split into two blocks of 72 trials (with 12 trials for each condition), randomized per participant and per block. Every participant executed one block of 24 practice trials ( 4 for each experimental condition and 12 control trials) equally randomized per participant. RTs and error rates were measured as dependent variables in every task.

The participants in the categorization group were instructed to rest their index fingers on the $V$ and $M$ keys for the lexical decision probe task. Also, the middle and third fingers of each hand had to be located on the $D$ and $F$ (left hand) and the $K$ and $L$ (right hand) keys to perform the categorization task. The participants from the letter search group also had to rest their fingers on the $V$ and $M$ keys for the lexical decision probe task and their middle fingers on the $\mathrm{F}$ and $\mathrm{K}$ keys for the letter search task. In both groups, the thumbs had to rest on the space bar in order to advance trials easily. Again, the instructions emphasized the need for speed and accuracy in every response.

\section{Results}

As a result of the trimming, $0.24 \%$ of the overall responses were discarded in Experiment 2. Means of median RTs to the probe display, standard deviations, and percentage of errors per group and condition are shown in Table 2 . We first analyzed the data for the letter search group on the basis of the presence of the target letter in the prime display. We observed a significant general increase of $25 \mathrm{msec}$ in the response to the probe display when the search letter was absent in the prime target word $\left[F(1,16)=41.89, M S_{\mathrm{e}}=3,997.21, p<.001\right]$, but the presence of the letter in the prime did not interact either with the experimental conditions or with the priming effects. Nevertheless, when the search letter was absent, a nonsignificant increase $(13 \mathrm{msec})$ in semantic priming from the target was found. This change in priming was not observed relative to the priming effects from the distractor (less than $2 \mathrm{msec}$ ).

Since the presence of the letter in the prime word did not interact with the priming effects, we collapsed the conditions corresponding to present and absent trials. The means of the collapsed median RTs are shown in Table 2 (collapsed condition). Accordingly, we conducted an ANOVA with condition (RA, RD, or UR) as a withinsubjects factor and task as a between-subjects factor (categorization or letter search). The task factor did not produce any reliable difference. However, condition $\left[F(2,60)=15.836, M S_{\mathrm{e}}=639.382, p<.001\right]$ and the condition $\times$ task interaction $\left[F(2,60)=11.230, M S_{\mathrm{e}}=\right.$ $639.382, p<.001]$ showed significant effects. The analysis of the interaction showed that distractor effects [UR-RD; $F(1,30)=9.283, M S_{\mathrm{e}}=1,134.595, p<.005$ ] and target effects [UR-RA; $F(1,30)=5.919, M S_{\mathrm{e}}=$ $1,400.974, p<.05]$ were significantly different, depending on the task.

In the categorization group, target words produced positive semantic priming $\left[F(1,15)=20.12, M S_{e}=791.63\right.$, $p<.01]$. However, negative semantic priming from distractors did not reach significance, although the direction of the difference was the expected one.

For the visual search group, distractors showed positive semantic priming $\left[F(1,15)=9.11, M S_{\mathrm{e}}=578.20, p<\right.$ $.01]$. The positive priming from the target word also reached significance $\left[F(1,15)=6.80, M S_{\mathrm{e}}=609.35, p<\right.$ .05].

Errors did not show reliable effects in any of the previous analyses. The posterior estimation of SOA was performed as in Experiment 1, showing a mean SOA of around 1,000 msec. No differences between the responses in the two prime tasks were observed, although there was an increase of about $30 \mathrm{msec}$ in the categorization task. 


\section{Discussion}

In this experiment, no differences were found between the two groups in the overall RTs to the probe displays. This finding could be taken to support the idea that it is task switching, and not the distance in the level of processing between the prime and the probe task, that increases overall RTs in designs such as that used in Experiment 1 (see Henik et al., 1994). However, such a conclusion cannot be drawn on the basis of the present experiment, since the categorization task and the lexical decision task from Experiment 1 are not exactly equivalent. Several factors may induce an increase in the RTs in the present experiment. For example, the number of alternative responses is greater for the categorization task (four responses vs. two for the lexical decision group of Experiment 1), so the prime response may be more difficult in that group. Also, in the present experiment, response keys change from the prime to the probe, whereas in Experiment 1 they were the same. These differences make the comparison between the two high-level processing groups (i.e., lexical decision and categorization) more difficult, so no clear conclusions can be extracted from overall probe RTs in this experiment.

In the present experiment, the letter search group showed significant semantic priming $(25 \mathrm{msec})$, whereas the corresponding effect in Experiment 1 was not significant $(15 \mathrm{msec})$. This increase in semantic priming apparently was due to the inclusion in the analysis of trials in which the target letter was absent. In those trials, target selection never took place, and attention might have been more easily focused on the word level. Indeed, semantic priming was $13 \mathrm{msec}$ higher when the letter was absent. This increase might reduce the apparent (although nonsignificant) difference observed in Experiment 1 between priming from the target and from distractors.

With regard to the priming effects from distractors, the results obtained here basically replicate those of the previous experiment. Indeed, distractors showed a tendency to produce negative semantic priming when the task involved the processing of high-level information (in categorization), whereas positive priming was again found when the prime task required letter processing. In both groups, there were changes of task, but still the direction of semantic priming changed from negative with categorization to positive when the task involved letter processing. It might still be argued that lexical decision was more similar to categorization than to letter search, in that categorization and lexical decision both required attention to the word level. However, all other aspects of the categorization and lexical decision tasks were different (i.e., number of response keys, presence of pseudowords, mapping between stimulus and response, etc.). Moreover, although in both cases attention was oriented to the word level, the type of information to be extracted from the word may have been quite different. The categorization task required access to the meaning, whereas the lexical decision task could be performed, in principle, without semantic access (Grainger \& Jacobs, 1996). Thus, if a change in tasks sufficed to produce a change in the direction of distractor semantic priming from negative (lexical decision and categorization groups) to positive (letter search groups), we would expect to see a difference between the lexical decision group from Experiment 1 and the categorization group from Experiment 2. However, the pattern of results in both groups is basically the same.

There appears to be no straightforward account of our results on the basis of task switching per se. We therefore return now to the inhibitory account of negative priming-in particular, a version suggested by Tipper et al. (1994).

Tipper et al. (1994) suggest that inhibitory mechanisms of selective attention may be modulated by the informational demands of the task being performed on the target stimuli. This account is particularly relevant here, since the prime task effect itself shows a modulation of priming by the goals of the task, and we have seen effects of task on distractor priming. Tipper et al. propose that inhibition may selectively act on those aspects of distractor representations that compete for the control of the current task. In our experiment, in the visual search group, it was, perhaps, the letters in the distractor word that were most likely to interfere with the task, rather than the distractor semantic representations. On the other hand, when semantic representations are relevant to the task (as in lexical decision or categorization), distractor semantic representations are inhibited, as we found.

In the general case, the complete suppression of every item of ignored information would be extremely nonadaptive, since we might need rapid access to some ignored information in order to program future actions (Allport, 1987). In addition, if inhibition is an opponent process reacting to activation (Houghton, 1994), it is likely that sometimes we will not see any effect of distractor processing, because the equilibrium level of activationinhibition may be close to resting levels. This point is important for studies that attempt to infer the absence of processing from the absence of priming (such as Henik et al., 1994). If we accept the possibility of the co-occurrence of activation and inhibition, acting on the same information, no definite conclusions can be drawn from the absence of priming effects (Houghton et al., 1996, make similar points regarding relationships between interference and priming).

\section{GENERAL DISCUSSION}

In this research, we investigated whether semantic processing of words requires attentional involvement. On the basis of the finding that when attention is directed to lowlevel features of words, semantic priming is reduced or eliminated, some authors (Henik et al., 1994; Kahneman \& Henik, 1981) have suggested that it is not a completely automatic process, since it can be voluntarily modulated. We have put forward the alternative proposal that semantic access in reading is indeed fluent and automatic but that, precisely because of this, it has to be controlled in 
relatively novel tasks, such as letter search. The words are automatically activated, but this activation is reduced or eliminated by inhibitory processes aimed at controlling prepotent response activation when it is not compatible with or useful for the target response.

We tried to distinguish target and distractor effects by using a negative-priming procedure. With this, we can separate effects produced by the target word (attention may be partially oriented to it because the relevant information - the letters - is contained in the same word) from those of a distractor word (attention is neither spatially nor conceptually oriented to it). Negative priming from distractor words should then have been observed.

Contrary to expectations, distractor words in a letter search prime produced positive semantic priming in a subsequent lexical decision (Experiments 1 and 2). This could not simply be due to the change of task, since negative semantic priming was observed when the task changed from categorization in the prime to lexical decision in the probe (Experiment 2).

\section{Semantic Priming and the Prime Task}

The main results reported here are (1) that processing of distractors as well as of targets is affected by task goals and (2) that reliable semantic priming can be obtained from word distractors even when the task requires nonsemantic processing of targets. This latter finding contradicts current theories based on the prime task effect, which claim that semantic activation from words does not occur when attention is directed to the letter level (see the discussion of Experiment 1 for a fuller account).

However, the reasons why positive semantic priming in lexical decision is reduced when the prime task is letter search still remain unclear. It is important to note here that we did not, in fact, find reliable differences in the amount of positive semantic priming caused by the targets and by the distractors in the relevant conditions. One possibility is that the observed facilitation from both is due to automatic semantic processing plus the withdrawal of attention from the semantic level. In other words, when attention is directed to the low-level features of a target word, what we obtain is the effect of the automatic activation of the word's semantics in the absence of any additional intentional component, as would be present in a lexical decision or categorization task.

However, this is not to exclude the possibility of a stronger reduction in the level of target word activation owing to strategic control of the level of representation required in the letter search prime. This control would not affect processing of distractor words, since no letters are being searched for in the distractors. There are some data that may support this possibility. For example, if attention is oriented to the ink color of the word in a Stroop procedure, the ignored word produces negative priming if it matches the ink color to be named in the following display (Dalrymple-Alford \& Bundayr, 1966; Neill, 1977). However, in a Stroop design, the response activated by the word is of the same type (a color name) as that re- quired by the task (ink color naming). Hence, we might assume that in a standard Stroop procedure, the degree of response competition generated is greater than that produced by the whole word when the task is to search for a letter (in the latter case, the word's name or meaning is not a member of the response set). If the degree of suppression is related to the degree of activation of competitors, this would explain the different results. Nevertheless, we should remark that Besner et al. (1990) did, in fact, report negative semantic priming from the relevant prime word during the search for a letter. The same case might be applied to other situations in which distractors compete more strongly for the response than does the target itself. In Yee's (1991) study, for example, participants had to attend to geometric shapes while ignoring words. In this case, the relative degree of activation of familiar words over unfamiliar shapes could result in the need for the inhibition of distractors even when they are not directly related to the main goal of the task. In our Experiments 1 and 2, however, this suggested prepotency of familiar (distractor) words over letters might be masked by the fact that the target is itself a word. In support of this idea, we have found, in further studies, that the direction of the semantic priming from distractor words in letter search tasks can be affected by the presence or absence of words in the target search string (Mari-Beffa, Houghton, Estévez, \& Fuentes, 2000).

\section{Mechanisms of Distractor Inhibition}

The results of these experiments are directly relevant for the behavioral goals account of negative priming (Tipper et al., 1994). When the prime task involves letter identities (letter search groups), distractor words appear to be automatically activated and cause semantic facilitation. On the other hand, when semantic representations are relevant to the task, semantic representations of distractor words are inhibited. Inhibitory control may be flexible enough to act on those representations that compete for the control of the action.

In line with this idea, in other negative-priming studies, we can observe a certain congruence between the nature of the negative priming found and the type of task being performed. When evidence for the inhibition of distractor identity is sought, researchers have mainly used identification tasks (Driver \& Baylis, 1993; Driver \& Tipper, 1989; Fuentes \& Humphreys, 1996). To obtain evidence for the inhibition of central/semantic representations of distractors, categorization and naming tasks are preferred (Beech, McManus, Baylis, Tipper, \& Agar, 1991; Tipper \& Baylis, 1987; Tipper \& Driver, 1988). To examine negative priming from locations, participants are asked to perform a localization task in the prime (Milliken, Tipper, \& Weaver, 1994) ${ }^{1}$

What is relatively new in our experiments is the pronounced change from negative to positive priming caused by distractors as a function of the prime task. Related findings were reported in the Tipper et al. (1994) study. When localization was the chosen task, identity of dis- 
tractors produced facilitation. Variables other than task type have also been found to lead to semantic facilitation from nonattended information. For example, Fuentes et al. (1994) found distractor semantic facilitation with words presented parafoveally under conditions of masking and dual tasks, reflecting the automatic nature of the semantic activation of words. Moreover, Fuentes and Tudela (1992) found a change of pattern from facilitation to inhibition, depending on the eccentricity of distractors. Furthest distractors produced facilitation, whereas others closer to the target produced negative priming. It seems likely that in the absence of inhibition, facilitation from distractors is the expected pattern. So, if we consider activation and inhibition as opponent mechanisms sometimes acting simultaneously on the same representations, we are very likely to observe a continuum from facilitation to inhibition, depending on different experimental procedures. When a reduction of positive priming is obtained (as in Henik et al., 1994) or even when no priming is found, this cannot be taken as evidence for the hypothesis that there was no processing of information.

\section{REFERENCES}

Algarabel, S., Sanmartín, J., García, J., \& Espert, R. (1985). Normas de asociación libre para investigación experimental. I [Free association norms for experimental research] (Informes de Laboratorio de Aprendizaje y Memoria: Informe no.1). Universidad de Valencia, Departamento de Psicología Experimental.

AlLPORT, D. A. (1987). Selection-for-action: Some behavioral and neuropsychological considerations of attention and action. In H. Heuer \& A. F. Sanders (Eds.), Perspectives on perception and action (pp. 395419). Hillsdale, NJ: Erlbaum.

Allport, D. A., Styles, E. A., \& Hsieh, S. (1994). Shifting intentional set: Exploring the dynamic control of tasks. In C. Umiltà \& M. Moscovitch (Eds.), Attention and performance XV: Conscious and nonconscious information processing (pp. 421-452). Cambridge, MA: MIT Press.

Beech, A., McManus, D., Baylis, G., Tipper, S. P., \& Agar, K. (1991). Individual differences in cognitive processes: Towards an explanation of schizophrenic symptomatology. British Journal of Psychology, 82, 417-426.

BESNER, D., SMITH, M. C., \& MACLeod, C. M. (1990). Visual word recognition: A dissociation of lexical and semantic processing. Journal of Experimental Psychology: Learning, Memory, \& Cognition, 16, 862-869.

Besner, D., Stolz, J. A., \& Boutilier, C. (1997). The Stroop effect and the myth of automaticity. Psychonomic Bulletin \& Review, 4 , 221-225.

Broadbent, D. E. (1958). Perception and communication. London: Pergamon

Carr, T. H., \& Dagenbach, D. (1990). Semantic priming and repetition priming from masked words: Evidence for a center-surround attentional mechanism in perceptual recognition. Journal of Experimental Psychology: Learning, Memory, \& Cognition, 16, 341-350.

Chiappe, P. R., Smith, M. C., \& Besner, D. (1996). Semantic priming in visual word recognition: Activation blocking and domains of processing. Psychonomic Bulletin \& Review, 3, 249-253.

Collins, A. M., \& LofTus, E. F. (1975). A spreading-activation theory of semantic processing. Psvchological Review, 82, 407-428.

COLMENERO, J. (1996). Influencias inhibitorias de la atención en la selección de informacion visual para la acción [Inhibitory influences of attention for the selection of visual information for action]. Unpublished master's thesis. University of Granada.
Dalrymple-Al Ford, E. C., \& Bundayr, B. (1966). Examination of some aspects of Stroop color-word test. Perceptual \& Motor Skills, 23, $1211-1214$.

DiAmOND, A. (1990). Developmental time course in human infants and infant monkeys, and the neural bases of inhibitory control in reaching. In A. Diamond (Ed.), The development and neural bases of higher cognitive functions (Annals of the New York Academy of Sciences, Vol. 608, pp. 637-676). New York: New York Academy of Sciences.

Driver, J., \& BAYLIS, G. C. (1993). Cross-modal negative priming and interference in selective attention. Bulletin of the Psychonomic Societv, 31, 45-48.

Driver, J., \& TipPER, S. P. (1989). On the nonselectivity of the "selective" seeing: Contrasts between interference and priming in selective attention. Journal of Experimental Psychology: Human Perception \& Performance, 15, 304-314.

Fox, E. (1995). Negative priming from ignored distractors in visual selection: A review. Psychonomic Bulletin \& Review, 2, 145-173

Francol.ini, C. M., \& EgETH, H. E. (1980). On the nonautomaticity of "automatic" activation: Evidence of selective seeing. Perception \& Psychophysics, 27, 331-342.

Friedrich, F. J., Henik, A., \& Tzelgov, J. (1991). Automatic processes in lexical access and spreading activation. Journal of Experimental Psychology: Human Perception \& Performance, 17, 792-806.

Fuentes, L. J., Carmona, E., Agis, I., \& Catena, A. (1994). The role of anterier attention system in semantic processing of both foveal and parafoveal words. Journal of Cognitive Neuroscience, 6, 17-25.

Fuentes, L. J., \& Humphreys, G. W. (1996). On the processing of "extinguished" stimuli in unilateral visual neglect: An approach using negative priming. Cognitive Neuropsychology, 13,111-136.

Fuentes, L. J., Humphreys, G. W., Agis, I. F., Carmona, E., \& Catena, A. (1998). Object-based perceptual grouping affects negative priming. Journal of Experimental Psychology: Human Perception \& Performance, 24, 664-672.

Fuentes, L. J., \& TUDELA, P. (1992). Semantic processing of foveally and parafoveally presented words in a lexical decision task. Quarterly Journal of Experimental Psychology, 45A, 299-322.

GATtI, S. V., \& EGETH, H. E. (1978). Failure of spatial selectivity in vision. Bulletin of the Psychonomic Society, 11, 181-184.

GlaSER, W. R. (1992). Picture naming. Cognition, 42, 61-105

Grainger, J., \& JacoBS, A. M. (1996). Orthographic processing in visual word recognition: A multiple read-out model. Psychological Review, 103, 518-565.

Henik, A., Friedrich, F. J., Tzelgov, J., \& Tramer, S. (1994). Capacity demands of automatic processes in semantic priming. Memory \& Cognition, 22, 157-168.

HOUGHTON, G. (1994). Inhibitory control of neurodynamics: Opponent mechanisms in sequencing and selective attention. In G. D. A. Brown \& M. Oaksford (Eds.), Neurodynamics and psychology (pp. 107155). London: Academic Press.

Houghton, G., \& TipPER, S. P. (1994). A model of inhibitory mechanisms in selective attention. In D. Dagenbach \& T. H. Carr (Eds.), Inhibitory processes in attention, memory, and language (pp. 53-112). San Diego: Academic Press.

Houghton, G., Tipper, S. P., Weaver, B., \& Shore, D. (1996). Inhibition and interference in selective attention: Some tests of a neural network model. Visual Cognition, 3, 119-164.

Juillan, A., \& Chang-Rodríguez, E. (1964). Frequency dictionary of Spanish words. The Hague: Mouton.

Kahneman, D., \& Henik, A. (1981). Perceptual organization and attention. In M. Kubovy \& J. R. Pomerantz (Eds.), Perceptual organization (pp. 181-211). Hillsdale, NJ: Erlbaum.

LHeRMitTE, F. (1983). 'Utilization behavior' and its relation to lesions of the frontal lobes. Brain, 106, 237-255.

MACLEon, C. M. (1991). Half a century of research on the Stroop effect: An integrated review. Psychological Bulletin, 109, 163-203.

Margolin, C. (1983, April). Automaticity of semantic priming: The effect of orienting task to the prime. Paper presented at the 63rd Annual Meeting of the Western Psychological Association, San Francisco. Marí-Beffa, P., Houghton, G., Estévez, A. F., \& Fuentes, L. J. 
(2000). Word-based grouping affects the prime task effect on semantic priming. Journal of Experimental Psychology: Human Perception \& Performance, 26, 469-479.

MCClelland, J. L., \& RumelharT, D. E. (1981). An interactive activation model of context effects in letter perception: Pt. 1. An account of basic findings. Psychological Review, 88, 315-407.

Meyer, D. E., \& Schvaneveldt, R. W. (1971). Facilitation in recognizing pairs of words: Evidence of a dependence between retrieval operations. Journal of Experimental Psychology, 90, 227-234.

Milliken, B., Tipper, S. P., \& Weaver, B. (1994). Negative priming in a spatial localization task: Feature mismatch and distractor inhibition. Journal of Experimental Psychology: Human Perception \& Performance, 20, 624-646.

MoOrE, C. M. (1994). Negative priming depends on probe-trial conflict: Where has all the inhibition gone? Perception \& Psychophysics, 56, 133-147.

NeELY, J. H. (1977). Semantic priming and retrieval from lexical memory: Roles of inhibitionless spreading activation and limited-capacity attention. Journal of Experimental Psychology: General, 106, 226254.

NeELY, J. H. (1991). Semantic priming effects in visual word recognition: A selective review of current findings and theories. In D. Besner \& G. W. Humphreys (Eds.), Basic processes in reading: Visual word recognition (pp. 264-336). Hillsdale, NJ: Erlbaum.

NeILL, W. T. (1977). Inhibitory and facilitatory processes in attention. Journal of Experimental Psychology: Human Perception \& Performance, 3, 444-450.

NEILL, W. T. (1997). Episodic retrieval in negative priming and repetition priming. Journal of Experimental Psychology: Learning, Memory, \& Cognition, 23, 1291-1305.

NEILL, W. T., LISSNER, L. S., \& BECK, J. L. (1990). Negative priming in same-different matching: Further evidence for a central locus of inhibition. Perception \& Psychophysics, 48, 398-400.

NeILL, W. T., \& Terry, K. M. (1995). Negative priming without reaction time: Effects on identification of masked letters. Psychonomic Bulletin \& Review, 2, 121-123.

NeumanN, E., \& DeSchepper, B. G. (1992). An inhibition-based fan effect: Evidence for an active suppression mechanism in selective attention. Canadian Journal of Psychology, 46, 1-40.

Neumann, O. (1984). Automatic processing: A review of recent findings and a plea for an old theory. In W. Printz \& A. Sanders (Eds.), Cognition and automatic processing (pp. 255-293). Berlin: SpringerVerlag.

Ortells, J. J., \& Tudela, P. (1996). Positive and negative semantic priming of unattended parafoveal words in a lexical decision task. Acta Psychologica, 94, 209-226.

PosNer, M. I., \& CARR, T. H. (1992). Lexical access and the brain: Anatomical constraints on cognitive models of word recognition. American Journal of Psychology, 105, 1-26.

POSNER, M. I., \& SNYDER, C. R. R. (1975). Facilitation and inhibition in the processing of signals. In P. M. A. Rabbitt \& S. Dornic (Eds.), Attention and performance $V$ (pp. 669-682). New York: Academic Press.

Reason, J. T. (1979). Actions not as planned. In G. Underwood \&
R. Stevens (Eds.), Aspects of consciousness (Vol. 1, pp. 67-89). London: Academic Press.

Sмrтh, M. C. (1979). Contextual facilitation in a letter search task depends on how the prime is processed. Journal of Experimental Psychology: Human Perception \& Performance, 5, 239-251.

Smith, M. C., Theodor, L., \& FrankLin, P. E. (1983). The relationship between contextual facilitation and depth of processing. Journal of Experimental Psychology: Learning, Memory, \& Cognition, 9, 697712.

STOLZ, J. A., \& BESNER, D. (1996). Role of set in visual word recognition: Activation and activation blocking as nonautomatic processes. Journal of Experimental Psychology: Human Perception \& Performance, 22, 1166-1177.

STROOP, J. R. (1935). Studies of interference in serial verbal reactions. Journal of Experimental Psychology, 18, 643-662.

TIPPER, S. P. (1985). The negative-priming effect: Inhibitory effects of ignored primes. Quarterly Journal of Experimental Psychology, 37A, 571-590.

TIPPER, S. P., \& BAYLIS, G. C. (1987). Individual differences in selective attention: The relation of priming and interference to cognitive failure. Personality \& Individual Differences, 8, 667-675.

TIPPER, S. P., \& CRANSTON, M. (1985). Selective attention and priming: Inhibitory and facilitatory effects of ignored primes. Quarterly Journal of Experimental Psychology, 37A, 591-611.

TIPPER, S. P., \& DRIVER, J. (1988). Negative priming between pictures and words in a selective attention task: Evidence for semantic processing of ignored stimuli. Memory \& Cognition, 16, 64-70.

TiPPER, S. P., Weaver, B., \& Houghton, G. (1994). Behavioral goals determine inhibitory mechanisms of selective attention. Quarterly Journal of Experimental Psychology, 47A, 809-840.

Treisman, A. M. (1969). Strategies and models of selective attention. Psychological Review, 76, 282-299.

VIVAS, A. B., \& FUENTES, L. J. (2000). Stroop interference is affected in inhibition of return. Manuscript submitted for publication.

YEE, P. L. (1991). Semantic inhibition of ignored words during a figure classification task. Quarterly Journal of Experimental Psychology, 43A, 127-153.

Zorzi, M., Houghton, G., \& ButTerworth, B. (1998). Two routes or one in reading aloud: A connectionist dual-process model. Journal of Experimental Psychology: Human Perception \& Performance, 24, 1-31.

\section{NOTE}

1. It is interesting to note that the naming task is more effective in this regard when the stimuli are pictures than when they are words (Tipper \& Driver, 1988). A probable reason for this is that the semantic representation of a picture is required for naming it (see Glaser, 1992, for a review of data and theories), whereas naming a word can, in principle, be performed exclusively from the orthographic codes without any semantic involvement (Zorzi, Houghton, \& Butterworth, 1998).

(Manuscript received July 6, 1998; revision accepted for publication July 16,1999 .) 